\title{
Correlation between Sex Stages and Leaf Numbers in Arisaema tosaense Makino (Araceae)
}

\author{
Yuko Muramatsu $^{1}$, Kanako Matsuyama ${ }^{1}$, Hiroshi Hayakawa ${ }^{2,3}$, Yukio Minamiya ${ }^{3}$, Katsura Ito ${ }^{3}$, \\ Ryo Arakawa ${ }^{3}$, Tatsuya Fukuda ${ }^{3 *}$ \\ ${ }^{1}$ Graduate School of Integrated Arts and Sciences, Kochi University, Nankoku, Japan; ${ }^{2}$ United Graduate School of Agricultural Sci- \\ ences, Ehime University, Nankoku, Japan; ${ }^{3}$ Faculty of Agriculture, Kochi University, Nankoku, Japan. \\ Email: ${ }^{*}$ fukuda@kochi-u.ac.jp
}

Received June $19^{\text {th }}$, 2011; revised July $1^{\text {st }}$, 2011; accepted August $15^{\text {th }}, 2011$

\begin{abstract}
Arisaema tosaense Makino develops either 1 or 2 leaves during both the male and female phases. To clarify the relationship between growth stage (sexual stage) and leaf number in this species, we conducted morphological analysis using A. tosaense, A. japonicum Bulme, A. sikokianum French. \& Sav., and A. ringens (Thunb.) Schott. We found that increase in size of pseudostem of these Arisaema species is correlated to changes in the growth stage from sterile to male and from male to female phases. In particular, 1-leaf individuals of $A$. tosaense appeared at the beginning of both male and female phases, suggesting that they contribute to the earlier appearance of the fertile phase from sterile stages.
\end{abstract}

Keywords: Araceae; Arisaema tosaense; Fertile Phases; Leaf Number; Morphology

\section{Introduction}

Some plants are known to change from male to female or vice versa during their lifetimes [1], but only has much attention been paid to understanding their life histories have not been clearly understood $[2,3]$. The most widely accepted explanation for changes in sex is the size-advantage model, which suggests that if an organism reproduces more efficiently as 1 sex, for example male, when small and more efficiently as the other sex (female) when large then changing sex from male to female with increasing size would be favoured $[4,5]$.

The genus Arisaema Martius belongs to the family Araceae and has characteristic flowers, which consist of a hooded tube and an elongated or rounded spadix inside the spathe [6]. Among sex-changing organisms whose life histories have been studied, plants belonging to this genus are unusual because they can change both their sex and size in either direction from one season to the next [7]. Moreover, the sex-changing sizes (sterile to male, male to female) were identified using some Arisaema species [8-10]. Within the section Pistillata Nakai in this genus, A. tosaense Makino is a sex-changing perennial herb that occurs in the evergreen forests of the Shikoku district of Japan. Its structure is simple, consisting of an underground storage organ (corm), 1 or no inflorescence,

"Corresponding author. a spadix-appendage that is clavate and thickened at the apex, and a green spathe-blade [7]. In particular, in this species, individuals with 1 compound leaf can be found as frequently as those with 2 leaves during both the male and female phases (Figure 1). A preliminary phylogenetic analysis of closely related species of $A$. tosaense (data not shown) showed that, for example, A. japonicum Bulme has the following characteristics: a spathe blade that is always shorter than the tubular part and strongly declined at the tip over the mouth; a tessellated stem,

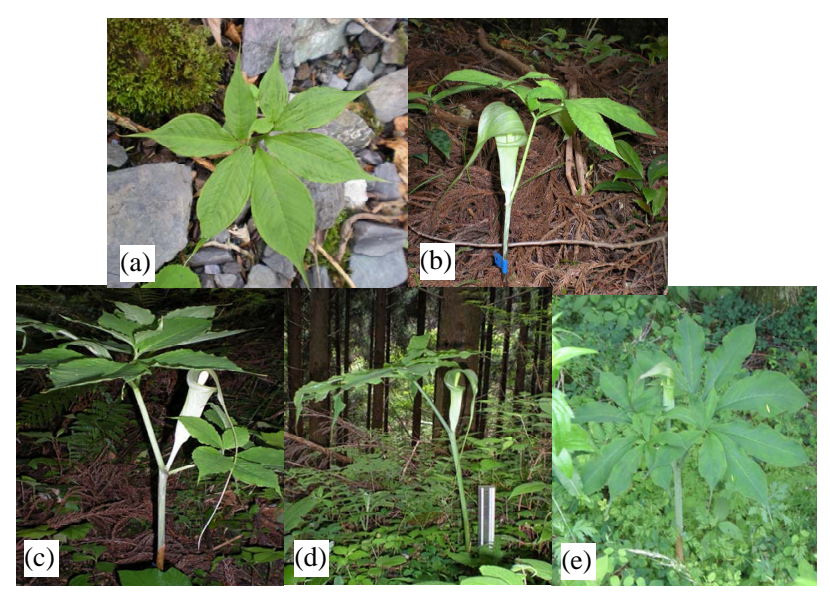

Figure 1. Leaf morphology of Arisaema tosaense. (a) Sterile; (b) Male with 1 leaf; (c) Male with 2 leaves; (d) Female with 1 leaf; (e) Female with 2 leaves. 
which actually consists of some leaf sheathes piled up around the flower stem; and 2 compound leaves. This indicates that $A$. japonicum always has a constant number of compound leaves, whereas $A$. tosaense can have either 1 or 2 leaves during both the male and female phases. In general, most species of the section Pistillata Nakai in Arisaema have constant number of leaves either 1 leaf or 2 leaves. However, it is very interesting that $A$. tosaense have both 1 leaf and 2 leaves.

In this case, it is very interesting to clarify whether the difference in the number of leaves during the male and female phases in A. tosaense correlates to increase in the plant size (pesudostem diameter); however, no studies have reported the life history of $A$. tosaense thus far. Therefore, to clarify the relationship between leaf number and growth stage (sexual stage) of $A$. tosaense, we conducted a morphological analysis of $A$. tosaense and allied taxa.

\section{Materials and Methods}

In this study, we analysed 4 Arisaema species: A. tosaense, A. japonicum, A. sikokianum French. \& Sav., and A. ringens (Thunb.) Schott. Between April and August of 2007, 2008, and 2009, we marked 247 sterile plants (Arisaema tosaense: 32; A. japonicum: 61; A. sikokianum: 36, and A. ringens: 118 individuals), 355 males (A. tosaense: 66 (1 leaf: 24; 2 leaves: 42 individuals); $A$. japonicum: 82; A. sikokianum: 63, and A. ringens: 144 individuals), and 251 females (A. tosaense: 42 (1 leaf: 3; 2 leaves: 39 individuals); A. japonicum: 47; A. sikokianum: 43, and $A$. ringens: 119 individuals) with numbered and staked wire flags in an area of Kochi Prefecture (Table 1). We measured the pseudostem diameter and the sexual state of each plant during the growing season in each year.

\section{Results and Discussion}

In general, the growth stage of Arisaema is reflected in the leaf area [8]; moreover, there are high correlations between the leaf area and the leaflet number, between the leaf area and the biomass, and between the leaf area and the pseudostem diameter $[9,10]$. Among these properties, we used the pseudostem diameter to clarify the relationship between leaf number and growth stage of A. tosaense. In our study, the pseudostem diameter of sterile, male, and female individuals of $A$. tosaense ranged from 1.1 to $5.4,2.4$ to 13.4 , and 6.7 to $20.0 \mathrm{~mm}$, respectively (Figure 2(a)). Of these, individuals of $A$. tosaense with 1 leaf and 2 leaves had diameters ranging from 3.1 to 7.9 $\mathrm{mm}$ and from 2.4 to $13.4 \mathrm{~mm}$, respectively, during the male phase and from 7.7 to 12.0 and from 6.7 to 20.0 $\mathrm{mm}$, respectively, during the female phase. In addition, the pseudostem diameter of sterile, male, and female plants ranged from 1.0 to $7.6 \mathrm{~mm}, 2.6$ to $14.3 \mathrm{~mm}$, and 4.2 to $27.4 \mathrm{~mm}$, respectively, in A. japonicum (Figure 2(b)); from 1.0 to $5.2 \mathrm{~mm}, 4.3$ to $12.5 \mathrm{~mm}$, and 7.4 to $23.2 \mathrm{~mm}$, respectively, in A. sikokianum (Figure 2(c)); and from 1.0 to $8.6 \mathrm{~mm}, 5.5$ to $24.4 \mathrm{~mm}$, and 11.4 to 42.5 $\mathrm{mm}$, respectively, in A. ringens (Figure 2(d)).

Our results indicate that increase in size of Arisaema species correlated to the growth stage from sterile to male and from male to female phases. Moreover, it was interesting to note that in $A$. tosaense, individuals with 1 leaf occurred earlier during growth than those with 2 leaves during both the male and female phases (Figure 2(a)), suggesting that individuals of $A$. tosaense with 1 leaf are likely to mature earlier from the sterile to the fertile stages. We observed that aerial shoots of A. tosaense expand from mid-May to June, which is later in the season than the expansion of aerial shoots of A. ringens, A. japonicum, and A. sikokianum [7]; however, the fruits mature fully in the same season (October to November). This suggests that the period of expansion of aerial shoots in $A$. tosaense is shorter than those of $A$. ringens, $A$. japonicum, and $A$. sikokianum and that the annual amount of photosynthate stored in the scape and

Table 1. Sampling localities used in this study.

\begin{tabular}{|c|c|c|c|}
\hline Species & Locality & Latitude & Longitude \\
\hline \multirow[t]{3}{*}{ Arisaema japonicum } & Kochi Prefecture, Kami City, Kahoku-Cho, Kawanouchi & $33^{\circ} 41^{\prime} 31^{\prime \prime}$ & $133^{\circ} 46^{\prime} 23^{\prime \prime}$ \\
\hline & Kochi Prefecture, Kami City, Tosayamada-Cho, Kamiananai & $33^{\circ} 410^{\prime \prime}$ & $133^{\circ} 37^{\prime} 19^{\prime \prime}$ \\
\hline & Kochi Prefecture, Nankoku City, Kuwanokawa & $33^{\circ} 39^{\prime} 42^{\prime \prime}$ & $133^{\circ} 36^{\prime} 14^{\prime \prime}$ \\
\hline \multirow[t]{2}{*}{ A. ringens } & Kochi Prefecture, Kami City, Kahoku-Cho, Iwakai & $33^{\circ} 36^{\prime} 54^{\prime \prime}$ & $133^{\circ} 45^{\prime} 33^{\prime \prime}$ \\
\hline & Kochi Prefecture, Nankoku City, Tochi & $33^{\circ} 31^{\prime} 46^{\prime \prime}$ & $133^{\circ} 36^{\prime} 39^{\prime \prime}$ \\
\hline \multirow[t]{2}{*}{ A. sikokianum } & Kochi Prefecture, Kami City, Kahoku-Cho, Iwakai & $33^{\circ} 36^{\prime} 54^{\prime \prime}$ & $133^{\circ} 45^{\prime} 33^{\prime \prime}$ \\
\hline & Kochi Prefecture, Nankoku City, Kuwanokawa & $33^{\circ} 39^{\prime} 42^{\prime \prime}$ & $133^{\circ} 36^{\prime} 14^{\prime \prime}$ \\
\hline \multirow[t]{4}{*}{ A. tosaense } & Kochi Prefecture, Kami City, Kahoku-Cho, Kawanouchi & $33^{\circ} 41^{\prime} 31^{\prime \prime}$ & $133^{\circ} 46^{\prime} 23^{\prime \prime}$ \\
\hline & Kochi Prefecture, Kami City, Tosayamada-Cho, Kamiananai & $33^{\circ} 411^{\prime \prime} 30^{\prime \prime}$ & $133^{\circ} 37^{\prime} 19^{\prime \prime}$ \\
\hline & Kochi Prefecture, Kami City, Tosayamada-Cho, Nishimata & $33^{\circ} 41 ' 28 "$ & $133^{\circ} 43^{\prime} 46^{\prime \prime}$ \\
\hline & Kochi Prefecture, Nankoku City, Kuwanokawa & $33^{\circ} 39^{\prime} 42^{\prime \prime}$ & $133^{\circ} 36^{\prime} 14^{\prime \prime}$ \\
\hline
\end{tabular}


$(\mathrm{N})$

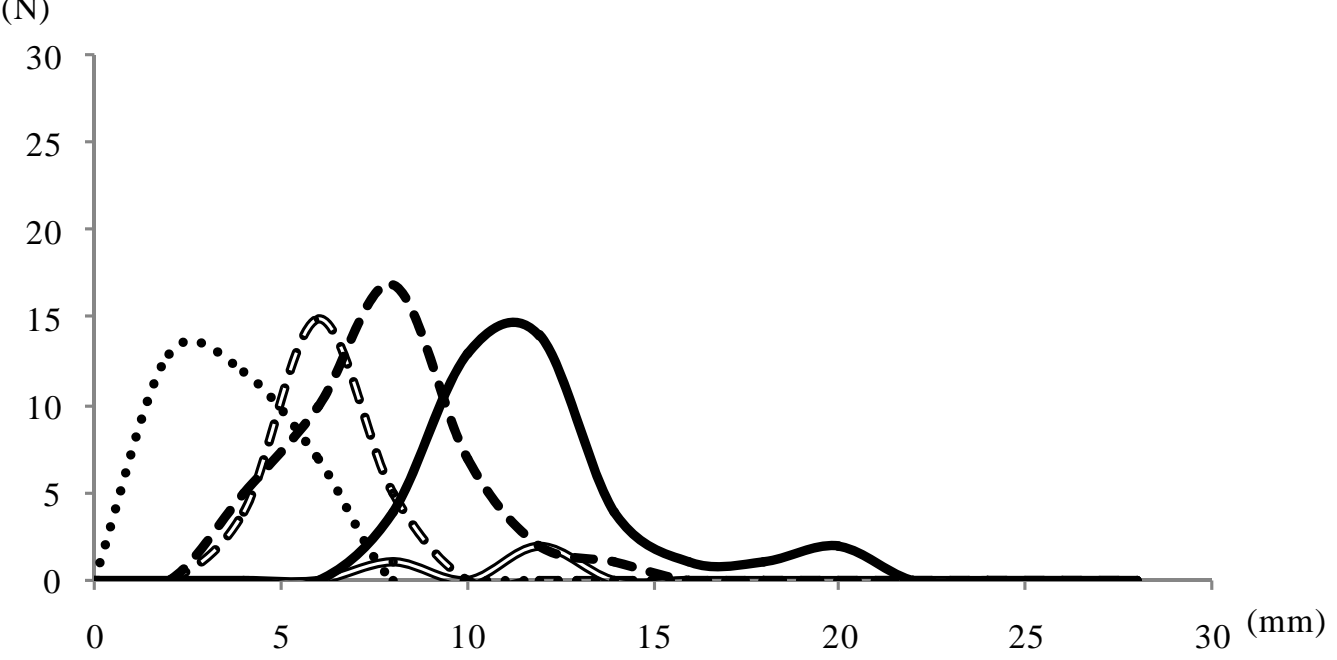

(a)
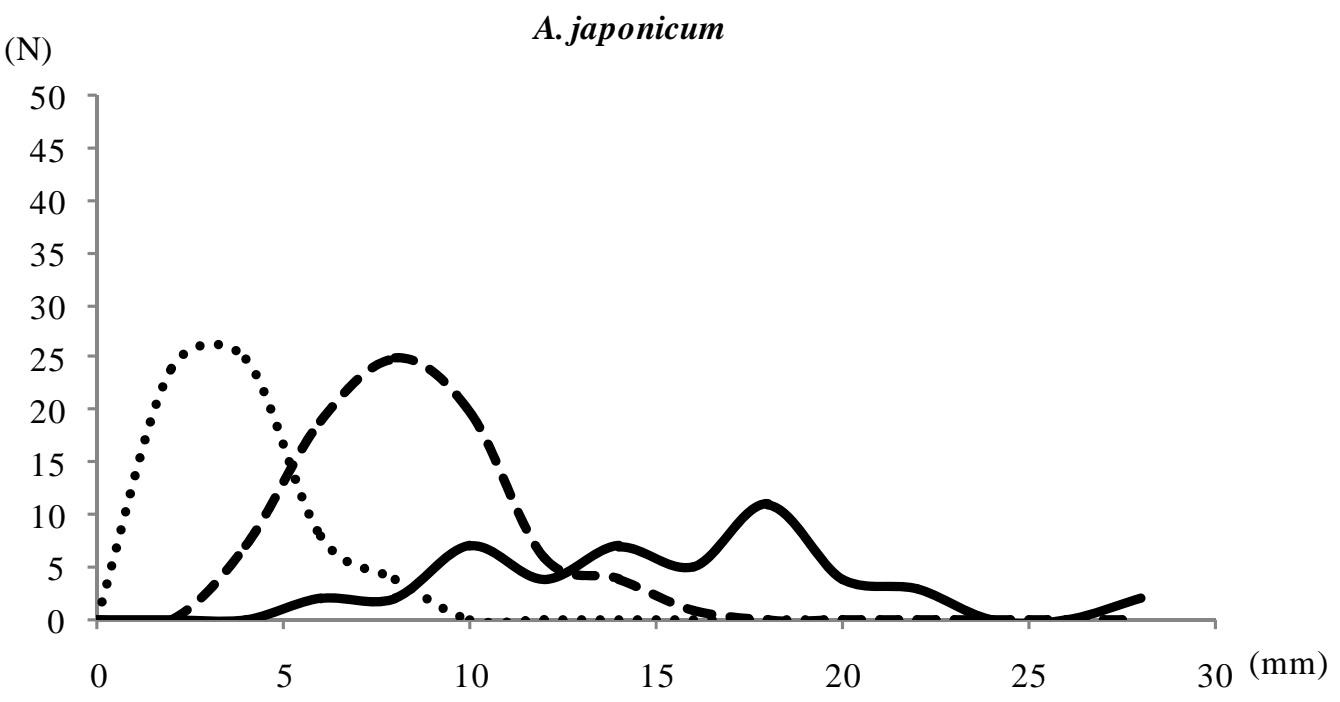

(b)

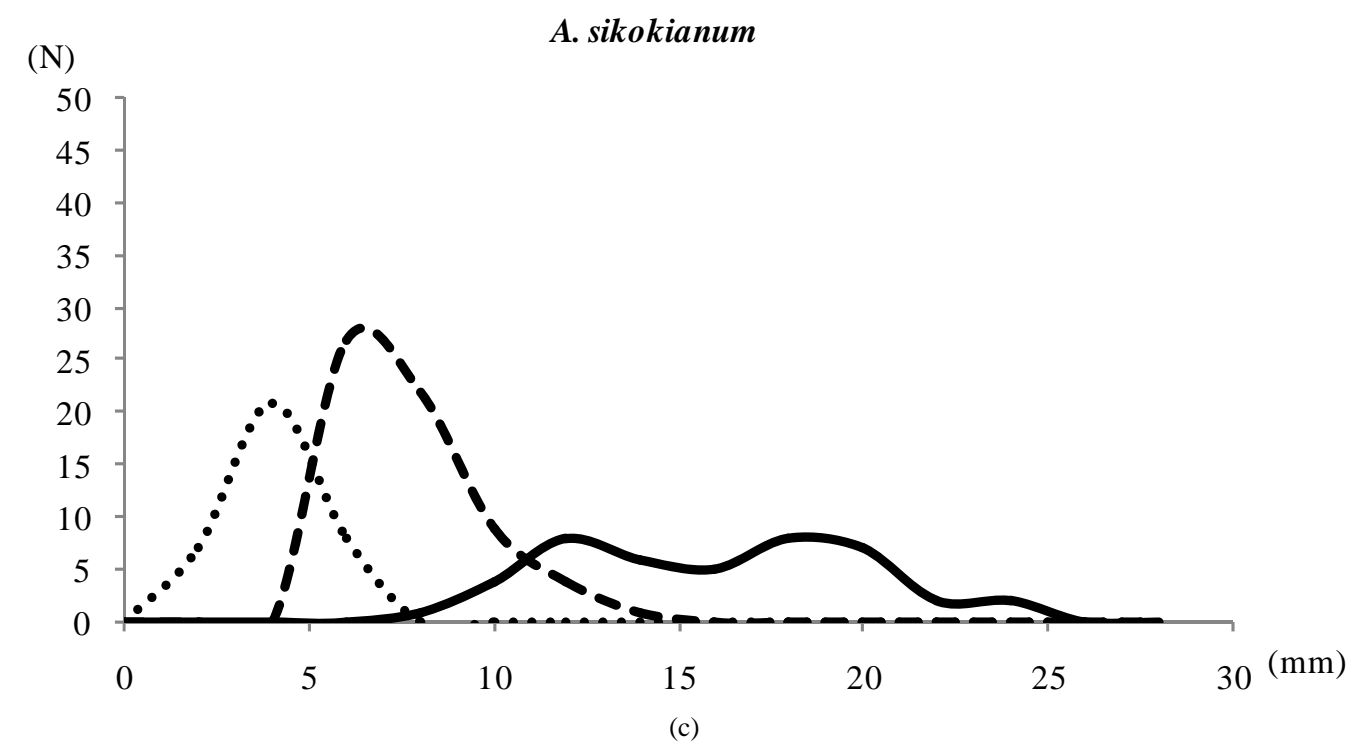




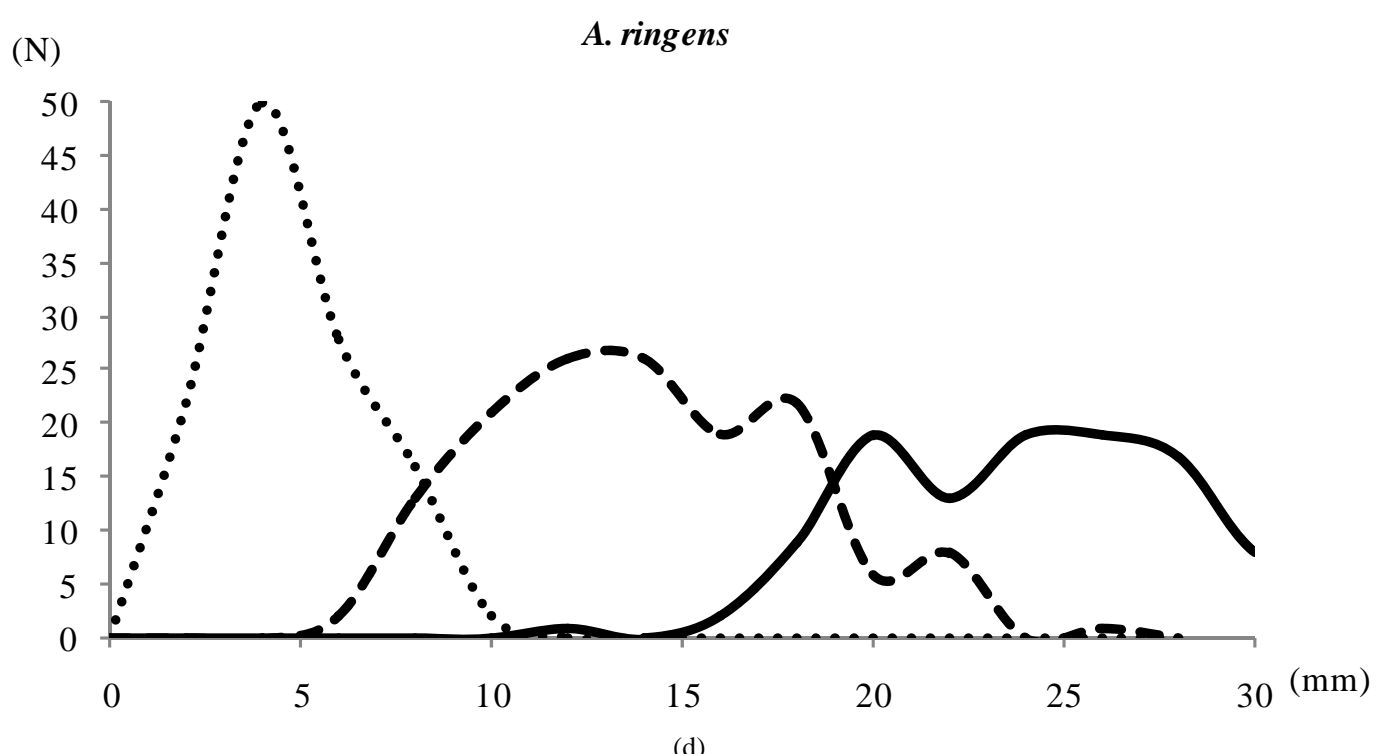

Figure 2. The relationship of growth stage and pseudostem diameter. The dotted line indicates the sterile phase; the white short dashed line, the male phase with 1 leaf; the black short dashed line, the male phase with 2 leaves; the white line, the female phase with 1 leaf; and the black line, the female phase with 2 leaves. (a) Arisaema tosaense; (b) A. japonicum; (c) A. sikokianum; (d) A. ringens.

corm of $A$. tosaense is smaller than that in the other species we studied. Therefore, the appearance of individuals of $A$. tosaense with 1 leaf may be a characteristic strategy enabling the plant to outcross in spite of a small amount of photosynthate at the beginning of the male and female phases.

In the section Pistillata Nakai in Japan, the species can be divided into 2 morphological groups, constant in 1 leaf type and 2 leaves type. For example, A. iyoanum Makino, a species growing high altitude, has a linear spathe blade that is ovate, gradually becomes acuminate, and always consists of 1 compound leaf (Figure 3(a)), although plants occasionally have a different number of leaves [7]. In fact, we found 1 large female with 2 leaves in the Omogo Valley, Ehime Prefecture (Figure 3(b)). There-

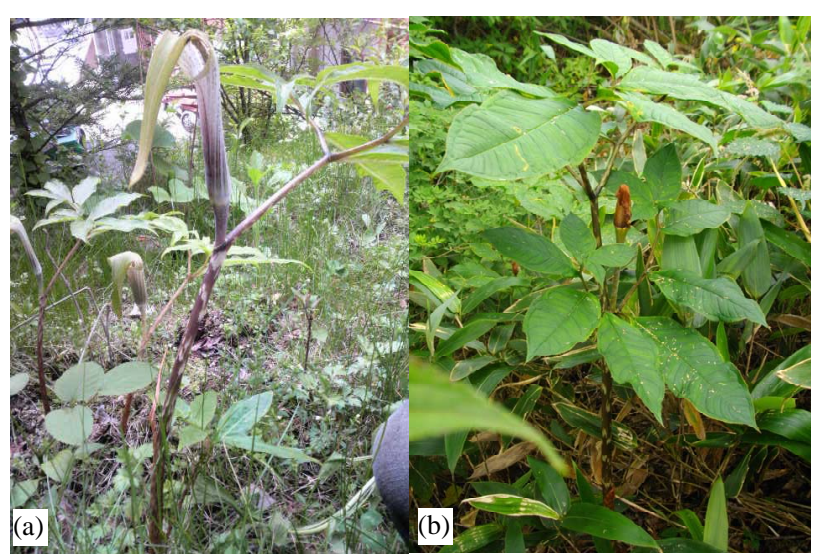

Figure 3. Arisaema iyoanum with 1 leaf (a) and 2 leaves (b) during the female phase. for in future, it will be interesting to analyze Arisaema species growing high altitude that always have 1 leaf, such as A. iyoanum Makino subsp. nakaianum (Kitag. \& Ohba) H. Ohashi \& J. Murata and A. longipedunculatum M. Hotta to understand the life histories and characteristic strategies of them, because individuals of $A$. tosaense with 1 leaf growing high altitude have a short photosynthetic period.

\section{Acknowledgements}

We wish to thank Drs. Yokoyama J., Hirata A., Tunala, Ueda R., Saito M., Ohga K., Yoshimi Y., Muroi M., Yokoyama N., Isomoto S., Miyata H., Tsuchiya Y., Usami A., Nagai H., Imayasu K. and Hamachi H. for providing much help. This study was partly supported by a Grant-in-Aid for Scientific Research from the Ministry of Education, Science and Culture of Japan (to T. F. and R. A.).

\section{REFERENCES}

[1] E. D. McArthur, "Environmentally Induced Changes of Sex Expression in Atriplex canescens,” Heredity, Vol. 38, No. 1, 1977, pp. 97-103. doi:10.1038/hdy.1977.10

[2] R. R. Warner, D. R. Robertson and E. G. Leigh, "Sex Change and Sexual Selection,” Science, Vol. 190, No. 4215, 1975, pp. 633-638. doi:10.1126/science.1188360

[3] E. L. Charnov, R. L. Los-den Hartogh, W. T. Jones and J. Van den Assem, "Sex Ratio Evolution in a Variable Environment,” Nature, Vol. 289, 1981, pp. 27-33. doi:10.1038/289027a0 
[4] S. Nanami, H. Kawaguchi and T. Yamakura, "Sex Change towards Female in dying Acer rufinerve Trees,” Annals of Botany, Vol. 93, No. 3, 2004, pp. 733-740. doi:10.1093/aob/mch093

[5] K. Kikuzawa, "Sex of Plants," In: K. Kikuzawa, Ed., Reproductive Ecology in Plants, Soju Shobo, Tokyo, 1995, pp. 69-130.

[6] J. Murata, "The Picture Book of Plant Systematics in Color Arisaema in Japan,” Hokurikukan, Tokyo, 2011.

[7] H. Ohashi, “Araceae,” In: Y. Satake, J. Ohwi, S. Kitamura, S. Watari and T. Tominari, Eds., Wild Flowers of Japan I, Heibonsha, Tokyo, 1981, pp. 111-122.
[8] P. Bierzychudek, "Determinations of Gender in Jack-inthe-Pulpit: The Influence of Plant Size and Reproductive History,” Oecologia, Vol. 65, No. 1, 1984, pp. 14-18. doi:10.1007/BF00384456

[9] H. Takasu, "Life History Studies on Arisaema (Araceae) I. Growth and Reproductive Biology of Arisaema urashima Hara," Plant Species Biolology, Vol. 2, No. 1-2, 1987, pp. 29-56. doi:10.1111/j.1442-1984.1987.tb00031.x

[10] H. Takasu, "Life History Studies on Arisaema angustatum Franchet et Savatier,” In: S. Kawano, Ed., Kyoikusha, Tokyo, 1988, pp. 54-79. 